\title{
How social capital can inform targeting formal social safety net interventions in vulnerable communities in eastern Ethiopia: an ethnographic case study
}

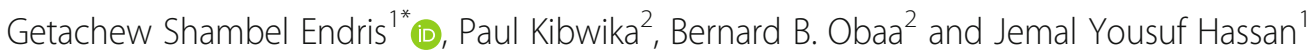

\begin{abstract}
Safety nets in Ethiopia are targeted and delivered in a context in which informal social capital practices also operate. But the role of social relations is largely overlooked in welfare programming. Understanding how social capital is mobilized and under which condition it enhances or constrains social safety net targeting may inform policy to design sustainable and inclusive welfare programs to improve household resilience. Using an ethnographic case study design, we studied the role of social capital in the implementation of a welfare intervention. Data were collected through observations and interviews with 30 households. Besides, data on household social network characteristics were collected using semi-structured interviews. The result suggested that greater access to social capital by a household enhances the efficiency of safety net targeting and delivery. Positioning the social transfer instruments within the broader sets of community social arrangements can optimize the allocation of scarce safety net resources and improves community relationships.
\end{abstract}

Keywords: Targeting, Humanitarian assistance, Social capital, Safety nets, Household resilience, Ethiopia

\section{Introduction}

The challenge of eliminating extreme poverty as articulated in the Global Sustainable Development Goal No. 1 is still enormous in Sub-Saharan Africa (SSA). Livelihood shocks continue to cause considerable welfare losses in the region. Despite rapid economic growth, $31 \%$ of the Ethiopian population is poor with $54 \%$ of its population classified as vulnerable to shocks (Demissie and Kasie 2017) and the majority of them living in rural areas. These shocks, by reducing the number of people engaging in a reciprocal relationship of mutual sharing, also disrupt the social setup that allows the poor to pool resources to insure against shocks.

\footnotetext{
* Correspondence: getchs2006@gmail.com

'Department of Rural Development and Agricultural Extension, Haramaya University, Diredawa, Ethiopia

Full list of author information is available at the end of the article
}

"Food aid" and "safety net" programs are common to help severely affected households to cope with food shortages. One of the principal challenges of humanitarian agencies operating in diverse and vulnerable communities such as in eastern Ethiopia is identifying an approach for effectively targeting and improving the resilience of households without undermining individual and collective capabilities and informal risk-sharing arrangements (e.g., del Ninno and Mills 2015; Devereux and Getu 2013; Gentilini and Omamo 2009). A call for an integration of formal and informal welfare systems have been made severally (Calder and Tanhchareun 2014; Devereux and Getu 2013). Nevertheless, the role that informal safety net ${ }^{1}$ plays in the implementation of

\footnotetext{
${ }^{1}$ It includes local social capital practices of risk-sharing and resourcepooling arrangements and networks such as labor-sharing networks, saving and credit groups, and burial associations. It operates based on culturally agreed norms of trust, moral obligation, and reciprocities.
} 
social protection programs remains largely misunderstood. This is despite a global recognition that social dynamics and local institutions mediate the delivery and impact of humanitarian actions. This study aims to generate an understanding of the role of informal mutual support arrangements, and the potential for complementarities between formal and informal systems.

With the intention to build on local capacities and the strengths of social relations, the Ethiopian government has for over 14 years been implementing a "social safety net approach" of humanitarian assistance, otherwise known as the Productive Safety Net Program (PSNP). Nonetheless, it is not clear how the program interacts with informal arrangements in its design and during implementation. Operationalizing the social safety net requires understanding the nature of informal arrangements, including the values of communality and accountability that underpin redistributive resource sharing. This study tries to understand how the social safety net program, as being implemented currently, integrates the indigenous forms of social protection with Babile District, Eastern Ethiopia, as a case study location.

Current implementation practices of the PSNP in Ethiopia and the study community suggest that targeting of safety net for the vulnerable households are undermined by fiscal and methodological (notably targeting) strains that often exclude the most disadvantaged households. Elite capture, spatial barriers, and information asymmetry in reaching intended beneficiaries are among the major problems resulting in high program transaction cost (Gentilini and Omamo 2009; Grosh et al. 2008; Monchuk 2014) and exclusion of needy recipients. How to integrate the local knowledge system and social networks in targeting safety net programs in identifying the deserving beneficiary is an area scholarly analysis is lacking.

Indigenous social capital, comprising diverse stocks of risk-sharing strategies involving social networks, norms, trust, and reciprocities such as credit networks, food, and labor sharing networks play an important role in mobilizing useful resources in Ethiopia (Aredo 2010; Pankhurst and Damen 2000). These arrangements have cushioned communities from adverse livelihood shocks and uncertainties (Bernier and Meinzen-Dick 2014; Bhattamishra and Barrett 2010; Aredo 2010; Kebede 2012; Kebede and Butterfield 2009). There is evidence that the application of these elements can increase the chances of success in implementing social transfer programs with positive outcomes for household resilience (Grootaert and van Bastelaer 2002; Woolcock and Narayan 2000). Situating social safety net programs within the broader package of community risk-sharing arrangements can aid in targeting the social safety net program. Gibbons et al. (2017) argued that localizing humanitarian response demands that humanitarian action should always endeavor to build on the capacities and abilities of the affected populations to provide assistance and protection to vulnerable communities in their own societies. The experience and collective wisdom of the indigenous people that are rooted within social networks can enhance the performance of the new safety net programs (Patel et al. 2012) in ensuring program accountability, transparency, enhancing inclusiveness and coverage, and sustainability. This is also in line with the principles of inclusive sustainable development and local solutions championed by major donors like the World Bank. But nature and role of the informal arrangements and the conditions under which they may enhance or constrain the targeting of social protection interventions in diverse and vulnerable communities are not clear. Examining the nature and role of the informal arrangements and the conditions under which they may enhance or constrain the targeting of safety net program will offer useful insights regarding how local knowledge and a social capital perspective can be considered into targeting humanitarian responses in vulnerable settings.

The key question guiding this study was how does social capital is mobilized and enhances or constrain the implementation of safety net program in Babile district of Eastern Ethiopia and with what outcomes. The study particularly examined how the different aspects of social capital interact with and influence the targeting of deserving beneficiaries and the distribution of social safety net resources within the community. The study draws the PSNP - a multi-year program designed to improve the resilience of the chronically food-insecure households.

\section{Background to the study site and the productive safety net program (PSNP)}

Babile, the study site, is located in eastern Ethiopia. Households in this part of the country are agro-pastoralists. The area is one of the most risk-prone zones in Ethiopia. It is characterized by erratic rainfall, frequent crop failure, recurrent conflict and drought, and livestock and human diseases. The mechanism for coping with such shocks depends on mutual support based on kinships and neighbors, seasonal migration, relief assistance, selling of household assets, etc. The PSNP is also being implemented in the district. The specific objectives of the program are to protect household asset depletion and creating additional household assets, ensuring household food availability, and ultimately building household resilience. Priority is given to the "chronically food-insecure" households. The program assigns beneficiaries in either of its two major components: (i) public work component (offers temporary employment in soil and water conservation, irrigation, rural road construction, etc.) and (ii) direct support (offers unconditional transfer for those who cannot provide labor) 
(Hoddinott et al. 2011; World Bank 2012, 2013). The targeted households receive payments for 6 months in a year; for the first 3 months, the beneficiaries are paid cash (ETB 280 or USD 14 per person) and for the other 3 months, they are paid in food ( $15 \mathrm{~kg}$ wheat and $5 \mathrm{~kg}$ beans per person) $)^{2}$. A household graduates from the program when it can meet its food needs and withstand modest shocks for a period of 12 months.

To achieve its envisaged objectives, the PSNP operates based on six core principles. These include (i) partnership between government and local people; (ii) continuity and predictability (ensuring regularity of resources transfer); (iii) productivity enhancement (involving program beneficiaries in different asset creating activities); (iv) avoidance of the dependency syndrome (by offering conditional transfer in exchange for labor contribution); (v) integration with district development plans; and (vi) flexibility (allow the utilization of the safety net resources in different livelihood improvement programs so long as the activities resonate with the Woreda ${ }^{3}$ food security plan). The number of beneficiary households in a particular community is determined based on a quota system. The kebeles are allocated quotas of beneficiaries from the districts. Identification of the vulnerable households is done by a taskforce, known as the "community food security task force" (CFSTFs), following the rules described in the program implementation manual (PIM) (Devereux et al. 2006). The CFSTF is comprised of the kebele political leaders (known as Ababgeres) and Development Agents (DAs) ${ }^{4}$. In general, four bodies take part in selecting beneficiaries; the Woreda Food Security Task Force (WFSTF), the Kebele ${ }^{5}$ Council, the Kebele Food Security Task Force (KFSTF), and the Community Food Security Task Force (CFSTF). The WFSTF is responsible for adapting the national guidelines on beneficiary selection criteria to make them relevant to the woreda and for training the KFSTF. The KFSTF is responsible for establishing a CFSTF in each village. The Kebele council is responsible for hearing appeals and resolving complaints. However, within the villages, safety net program is not well targeted. It is also insufficient both in coverage and the amount of transfer to individual households. As a result, many people, including program beneficiaries, have continued to experience acute food insecurity.

\footnotetext{
${ }^{2}$ This amount was calculated at the time of data collection (between 2014 and 2017)

${ }^{3}$ Woreda (plural woredas), often used interchangeably with the English term "district," is an administrative system in Ethiopia. A single woreda is made up of several kebeles.

${ }^{4}$ These are trained agricultural development workers in rural areas.

${ }^{5}$ Kebele (plural kebeles) is the smallest administrative unit in Ethiopia. It is often used to interchangeably with the English term "peasant association." Approximately, a single kebele comprises 500 households.
}

\section{Contextualizing social capital in development}

Social capital is composed of several entities. Putnam (1993) recognized the multidimensional nature of social capital and operationalized it as connections among individuals-social networks, organizations, and the norms of reciprocity and trustworthiness that arise from them. Coleman (1988) further extended Putnam's view by adding the role of "social structure" in which social relations and mutual support embedded under. Thus, social capital is derived from some aspects of social structure (consisting of relationships and networks) and facilitation actions of actors (norms, beliefs and attitude) within the structure that govern such relationships. The transformative capacity of the social structure into a mutually beneficial gainful action is generally collective action. Thus, norms of reciprocity, trust, and effective sanctions are important forms of social capital; the closure of networks and appropriate social organization facilitate the social structures for certain purposive actions in current and future. Social capital can thus be regarded as an investment rooted in social structure of relationships which are mobilized by individuals and communities to fulfill certain mutually beneficial collective action. In other words, investment in social relations by individuals is the means through which they gain access to embedded resources to transforming and insuring themselves against future uncertainties.

The transformative mechanism through which social capital redistributes resources are through bonding (horizontal networking), bridging, and linking (vertical connection) type social capital (Aldrich and Meyer 2015). Bonding connections connect people of homogenous characters horizontally (Mouw 2006) to accessing immediate assistance aftershocks. Conversely, bridging connections bring members across different networks and geographic boundaries. Linking social capital is a vertical network that links individuals with people of authorities and across institutions to help the poor leverage resources. Understanding social capital (as bonding, bridging and linking capitals) is the key to understanding the value of social interaction for effective localization of humanitarian response in vulnerable contexts (Mpanje et al. 2018).

To accommodate the different perspectives and aid understanding the role of social capital in the Ethiopian context, social capital can be operationalized as both a structural (social) and a cultural or cognitive phenomenon (Grootaert and Van Bastelaer 2002). While structural social capital is related to the networks, groups, linkages, and practices, the cognitive aspect refers to the attitudes, values, beliefs, and norms that govern interaction between people. These two dimensions are expected to interact in a dynamic manner to reinforce cooperation between community members to improve household wellbeing. 
To understand the role of social capital and draw policy implications, social capital is further divided into four major perspectives (Woolcock and Narayan 2000): (i) the communitarian view (referring to civic groups, associations, and clubs); (ii) the network view (referring to informal institutions, such as networks of friends, neighbors, and mutual support groups); (iii) the institutional view (referring to linkages with formal institutions or linking social capital); and (iv) the synergy view (referring to public and private partnership). In this study, we rely on the network view of social capital to examine the role of social capital in development program, and hence social capital is understood as networks of friends, neighbors, kin, and mutual support groups.

The literature on social capital and development programs suggest that the application of social capital can have a multiplier effect and optimizes the chances of success in the implementation of social transfer programs by among other things; minimizing transaction cost, increasing availability to information on the needy (Ballet et al. 2007), and reducing opportunistic behavior among community members (Grootaert and van Bastelaer 2002; Patel et al. 2012). Studies suggest that the different aspects of social capital may influence the targeting and distribution outcomes of food security interventions in vulnerable communities (Caeyers and Dercon 2012; Clarke and Dercon 2009). For example, Dercon and Krishnan (2003) found evidence that the presence of community informal risk-sharing arrangements is positively associated with a greater targeting performance of food aid programs, suggesting that it may allow for the wide dispersal of food resources received from the program into the larger community including to non-beneficiary households thereby reducing targeting errors. Heemskerk et al. (2004) also found similar evidence from a cash transfer program indicating that the wide presence of a functional social capital may generate positive spillover effect that goes beyond the immediate beneficiaries of the program. In contrast, the literature warns that not everything about social capital is good-differences in access to social capital resources arising from wealth and household demographic characteristics may bring the opposite effect. According to Bourdieu (1986), the degree to which a household is able to draw resources may be influenced by several factors, including network size, membership diversity (network diversity), or amount of capital possessed by each of those network members to whom the household is connected to as well as the location of the networks (network proximity). Studies show that (e.g., Bernier and Meinzen-Dick 2014) informal arrangements are not always indiscriminate and benign - they may benefit some individuals more than others to the detriment of marginalized groups. For instance, Petrikova and Chadha (2013) and
Clarke and Dercon (2009) found evidence that people with higher levels of social capital were more likely to be part of a social program as compared to those with smaller networks. Heemskerk et al. (2004) also found evidence that a household may derive greater resources from its network if the head has a higher educational level, regularly takes part in group activities, and holds a leadership position in the group. All these cases imply that social capital is an inevitable element in social development, and building resilience of the poor which if neglected may result in costly and ineffective interventions that cannot be sustained after the intervention to achieve resilience. In rural Ethiopia, social relations and mutual support are embedded under a complex social structure. As such, attempts to study social capital and its links with a social transfer intervention need to take into account not only the social and economic structure of the community but also the power structure within which the poor operate to mobilize resources using social networks.

\section{Methods of the study}

A qualitative ethnographic case study research design (Brewer 2000; Atkinson and Hammersley 2007) was followed to address the research questions. The ethnographic case study design is appropriate because the purpose of the study was to understand the role of social capital in shaping safety net targeting practices and outcomes for beneficiaries and non-beneficiaries of the program. Behind these phenomena is a social context against which formal and informal systems are embedded, shaping and reshaping actions and practices of intervention policies and programs (Long 2001). An ethnographic case study allows us to understand the "social life" of the intervention (Long 2001) as it implemented in the local people's context, perceived and utilized by the community members. This is by closely studying social actors (beneficiaries and non-beneficiaries) and their social networks in a naturally occurring settings and capture multiple perspectives of people's accounts, meanings, and actions on everyday context (Brewer 2000; Atkinson and Hammersley 2007). Being an ethnographic case study, the study combined both ethnography and case study. It is ethnographic because it looks at social networks as a socio-cultural process. It is a case study because it allows for an indepth understanding of a phenomenon within a research setting with clear boundaries (Creswell 2007).

Field work was conducted in one selected Kebele of Babile District of eastern Ethiopia between 2014 and 2017. The study site, Berkelle is one of the 18 safety net receiving Kebeles found in Babile District. The site was purposively selected to gain an in-depth insight on impacts and lesson learned considering the following criteria: (i) the kebele was pioneer in implementing the 
PSNP program so that we can learn impact better; (ii) the kebele has similar experience in participating in similar researches; (iii) the kebele is located in close proximity to the main road and town, and (iv) the administration and community were willing to participate in the research and welcomed our presence. Administrative and development activities (including safety net program) are organized based on Kebele lines in Ethiopia. Thus, kebeles are considered as communities in this study.

A total of 30 households were sampled and interviewed at least twice within the 4-year period. The categories interviewed included current safety net beneficiaries and nonbeneficiaries of safety net program. In addition, in-depth interviews were conducted with some key informants including mutual support group leaders, local elders and Abageres (a form of kebele political leaders who have a stake in PSNP targeting), and development agents (DA's) on several issues. Additional data on household social network characteristics were collected from 70 households using semi-structured interviews. In all cases, household size, sex, and seniority to the program were considered in the selection of respondents. All the respondents mentioned in this study were identified by their pseudonyms.

Ethnography is multi-modal. A complementary set of multiple data collection techniques were used to cover the various aspects of the study and ensure trustworthiness and reliability. On-site observations and semi-structured and unstructured in-depth interviews were used (following Brewer 2000). On-site/participant observations allowed the researcher to capture social meanings and ordinary activities by involving the researcher participating directly in the setting and enter the world of the people under study. Observation was made on several occasions, including during safety net payment days by following people directly to the distribution center and during the sharing of the safety net (wheat and oil) and the individuals they share it with. We also participated in informal discussion with the local people about safety net targeting. Since there were multiple settings, the research team used to divide observation sites. While observing, the researchers were taking extensive information and discuss it every night. To examine the seasonal variations in the performance of social networks and mutual support practices, both time interval and continuous observations were made between 2014 and 2017. Over the 4-year period, the researchers closely observed the seasonal changes in agricultural production and how this influenced household food consumption, sharing, and mutual support behavior in networks and mutual support groups.

In-depth interviews were conducted with various categories of respondents. To facilitate a more focused exploration of the subject, a semi-structured interview schedule was followed during individual interviews. However, towards the end of the fieldwork, the researchers depended entirely on unstructured conversation to acquire thick descriptions and validating responses. The interview guide consisted of questions on the respondents' behavior, opinion, feelings, knowledge, and socio-demographic characteristics. The checklist was pilot-tested beforehand in similar communities. Ambiguous concepts and theoretical ideas difficult to operationalize and understand were revised. Some questions in the checklist were accompanied by vignettes; hypothetical or real scenarios put to respondents for their comments pertaining how they would respond or imagine a third party behaving. All interviews were recorded using digital audio tapes and field notes. The field notes have date, time, location, and identities of the person involved. Prior to the interview, the researchers read the interviewee a consent form and summary of information. The document included a brief overview of the research, confidentiality, and consent (signed by the interviewee) that they are being audio taped.

In general, the data collection focused on looking evidences together that are indicative of the role of community networks towards program targeting, the broader sharing of the benefits of safety net between beneficiary, and non-beneficiary households within and outside the community. Social network data were collected on household social network characteristics (network size, composition, and proximity) for resource access and reciprocity, focusing from whom households have received social safety net transfer, relationship to the person, frequency of assistance received, and the location of the person (Marsden and Campbell 1984). Information on respondents' gender and location were collected to examine whether inter-household differences based on these variables may be related to differences in social networks and access to social safety net resources between households.

An iterative and reflexive process was used throughout the data collection (Brayman and Burgess 2005) and analysis process. This approach supported the researchers in collecting useful data throughout the data collection process and look for additional information for the next step of the data collection (Ortlipp 2008). Thus, to guide the next step in data collection, already available data was analyzed in a rapid and preliminary way. This allowed identifying gaps in information (e.g., through seemingly inconsistent information indicating that there was a "missing link") as well as to identify possible explanatory variables that could be checked for validity during the next interview, or key informant interview and then amended as necessary. Once fieldwork was completed, the data was analyzed using rapid analysis (Beebe 2001) and interpretive discourse analysis (Hardy et al. 2004). The rapid analysis was conducted 
after each data collection process so as to identify additional information (Beebe 2001) that are needed in the research. For instance, the in-depth interviews with sampled households in the community indicated links between household social network characteristics and access to safety net resources. The following discussion was used to explore household factors that enhance or constrain household access to social networks for accessing resources. These factors were then used in other in-depth interviews and other methods to crosscheck and validate information and causal links between the different aspects. Interpretive or relational content analysis (Hardy et al. 2004) was applied to analyze qualitative data collected through in-depth interviews and field observations. Interpretive content analysis approach integrates content and discourse analysis. Such data was analyzed and categorized by looking not only at the text (or content analysis part) but also its relationship to its context where meanings are produced to the intention of the producer of the text or reaction of the intended audience (discourse analysis). In general, following Creswell (2007), ethnographic data was analyzed following five major steps: data organizing, coding and developing theme, describing, interpreting, and representing. First of all, since all interviews were conducted in Afan-oromo language, interview transcripts were first transcribed to Afan Oromo and then translated to Amharic and English, respectively. Then, the researchers organized data using MS word. Each interview transcript was separately identified by file name that identifies each from others. Qualitative data were then coded line by line and organized into themes. To gain an in-depth understanding of personal stories and interview responses for each respondent, the transcriptions was read and reread repeatedly. The coded interview transcripts were then categorized using predefined concepts and additional coding categories emerged during the coding process. Major themes that emerged in the categorization include social safety net targeting, social networks in targeting safety net and resource sharing, household network characteristics, and household factors determining household access to social networks and social safety nets. Based on the themes emerged, sections with similar themes were merged accordingly.

In general, data were triangulated using multiple data sources and methods of data collection; structured and unstructured interviews and on-site observations. Accordingly, to triangulate data, the researchers checked interview data against observations from all the researchers. The researchers did not find any substantial differences among these sources.

\section{Results and discussions}

The results of this study explain the key features of the social safety net program, namely, targeting of safety net and how social capital is or is not considered in the process, and the resultant social effects on the intended beneficiaries. The results also explain how the key features of social capital influence the targeting of social safety net program. The data for this study was accessed using qualitative methods. The questions which this study addressed relate to the beneficiaries, nonbeneficiaries, implementing agencies, and their experiences in the safety net program. The result was based on key questions: how is the safety net targeted in the case study community? How do people perceive about the safety net program? How do the different actors (beneficiaries, non-beneficiaries, and other targeting agencies) participate in the process? How do people (beneficiaries and non-beneficiaries) share resources through social networks? How do the characteristics of social networks mediate household access to the safety net resources? The results were presented, discussed, analyzed, and interpreted using major themes and narratives. The major themes were social safety net targeting, social networks and resource sharing, household social network characteristics, and household factors determining access to social networks and social safety nets. The themes and supporting quotations for those themes are presented for each aspect of the questions.

\section{Targeting the public safety net}

Beneficiary selection or targeting-setting rules and practice for allocating benefits to the neediest members of society-is at the heart of social safety net transfer. The role of effective targeting is especially evident in communities such as "Babile" where needs are greatly relative to available resources. In this case, the choice of appropriate targeting is crucial to carefully target scarce resources to the poorest segments of the population. However, this is often easier said than done. Often problem arises when people are targeted using pre-defined criteria using concepts that are not locally understood. In this case, an important source of tension (between local people and selection taskforces) in the targeting of safety net to the poor at local community level arises from the conceptual understanding of "who is and who is not poor?" and the concept of "poverty" itself. For instance, in the study site, often beneficiaries were identified using key household poverty indicators as specified in the program implementation manual (PIM) for PSNP_considering the assessment of household asset ownership and household food security status (by making a distinction between concepts of chronic and acute food insecurity). The latter focuses on household deficiencies in food consumption, and this is done by combining self-targeting with government-defined standard indicators of food insecurity-with more than 3 months of food shortage in the previous year being the indicator 
of food insecurity. How these parameters are subjective and how they are applied in a specific context exclude would-be beneficiaries. This is where social capital founded within the community social support system would be instrumental to ensure fairness by allowing the community to participate in the identification of the needy households that desperately deserve support from the safety net.

Another problem was that the procedure for beneficiary selection itself was problematic. In the research sites, the process of beneficiary selection starts with a comprehensive profiling of the households in the villages. In such processes, the sources and amount of data available about a household are critical. In the study sites, very limited information is available. In practice, identification of beneficiaries was affected by availability of detailed information about vulnerable households. When the criteria for identifying the beneficiaries are externally determined like it was in this case, all members of the community feel they are entitled since this is a government program. The challenge arises from the extent to which the community is involved in determining the beneficiaries, including generating socially acceptable information about the households.

There was the difficulty of identifying the most needy households due to a lack of detailed information. Often, the screening of beneficiaries by CFSTFs is conducted by consulting a repository or a document that has the names of Kebele residents. This document hardly provides detailed information about the asset endowments and food insecurity situation of the households. As a result, targeting vulnerable households were mostly carried out by relying on the personal memories, knowledge, and subjective judgment of DAs and Abageres who have limited information about the vulnerability status of the households in the Kebele. With this limited information about households and lack of community involvement made the process less transparent and highly contentious within the villages. This is demonstrated by a large number of households excluded and claims that the CFSTF erred in their decisions. Majority of households (27 out of 30) including beneficiary households believed that assessment was not made based on accurate information regarding the actual vulnerability status of households. In this light, people argue that the criteria applied do not take into account the social dynamics and the local context-mainly referring to the local understanding of poverty and affluence as opposed to the scientific construct of poverty and food insecurity used in the PIM. This is contrary to what is stipulated in the PIM that permits adapting the national guideline for beneficiary targeting based on the local context. There was a feeling that the community is best placed to define realistic and inclusive criteria for identification of the beneficiaries but they are not involved. Food insecurity, for example, is not merely associated with a lack of land to cultivate food but there are several other social factors related to it, which the community understands better than the CFSTFs. For instance, Ahmed is a 45-year-old school guard with 7 children from Babile. He narrated his exclusion experience as the following:

I do not understand how households were assessed. I have an ailment and have not been able to farm for almost ten years now and I have to feed my seven children. I have land but could not lease it out for income because it is located near a conflict prone area with bordering Somali pastoralists. The only source of income I have to make ends meet is a 300 birr salary (equivalent of USD 15). I have been looking forward to PSNP to assist me but I have not been enrolled because I am considered to have a salary and I have land. Yet I see many who are in better position than I am getting enrolled into the program. They cannot consider my health status. I have been relying on my neighbors for support but this cannot be sustained much longer. My children are severely malnourished and I can't bear seeing my children die of hunger. Several times, I have contemplated committing suicide.

Such a case depicts not only a lack of appropriate information about households but also using indicators that are not realistic. Having a salary without taking into account how much is earned in relation to the family needs, and ownership of land without taking into account its usage, is unrealistic and unfair. The problem is that the government manual makes a simplistic assumption that there is a clear demarcation between the two forms of food insecurity (transitory and chronic) at the local community level. However, in practice, there is a fine line between the two forms as the two often overlap. Such blurred classification of food insecurity adopted by the manual of PSNP always has a tendency to exclude deserving beneficiaries, often making target susceptible to abuse and bias. The hope for some of the individuals like the school guard, Ahmed, in the above case is support from social networks and migration. Support from the neighbors (a form of social capital) is what sustains this family with the hope that a solution (like the safety net program) might emerge.

The officials responsible for the implementation of the program claim it is too costly to generate detailed vulnerability information for every household so that they had to rely on best available indicators. However, it should be noted that the community has more reliable information about each household and if engaged, would enable better decisions at no cost. 
Kedir is an official working in the food security bureau for over a decade and a member of the taskforce. He mentioned the following:

We need to find a cost effective method of identifying the poor to increase coverage of the needy households. The criteria we use to identify beneficiaries often defeat the very purpose the program. The statistics from the district office show that most of the needy recipients are not getting the support due to deficiencies in information about households. Some of our workers also exploit this to abuse the system to give food to those who do not deserve.

Even within such situations, the involvement of the community is the cheapest way to ensure equity and fairness. The social capital of the community is in itself an institution with rich data that would be exploited for better targeting of the beneficiaries of such a program.

People in Babile have their own ways of categorizing households in the basis of poverty. This is part of the community's indigenous knowledge that is being used by mutual support groups for a long time. For instance, with regard to wealth, the community categorizes households as Tujara (the rich), Woya (middle class), and Miskina (the poorest). Each of these wealth categories are further operationalized based on possession of different livelihood assets. The Miskina's are the ones that have chronic food insecurity. However, what happens most of the time is that the Tujara and Woya categories are the ones targeted to safety net program. During our field work, several households reported that this is currently becoming a source of social tension and resentment between beneficiaries and non-beneficiaries of safety net program, and the food security taskforces.

The community's way of categorizing household if applied or at least integrated within the existing formal targeting procedure would not create tensions in the community between beneficiaries and non-beneficiaries. Otherwise, the program introduced ill-feeling amongst community members, in a way destabilizing a community that would be otherwise stable and cohesive even with their challenges of food insecurity. The tensions created in the community will probably have a more long-lasting impact than the food crisis.

One of the local leaders expressed it this way:

In my view, the agencies are trying to unnecessarily complicate matters to exclude more poor people. The program must fit in our social context including our social categorization as defined by the community. We have a socially acceptable categorization of the community members which this program has distorted.
The fundamental reason for categorization and screening of the beneficiaries is that the program does not have enough resources to provide for the entire community in which $95 \%$ of the households are classified as poor. To ensure equity and transparency in such circumstances, relying on the local knowledge and societal stratification is critical. In the social stratification by the community, there are relations, which are part of the social capital rooted in the community's local knowledge. Involving community members in defining the social categories in a way strengthens the social ties, trust, and mutual support instead of creating tensions like it happened in this case. This finding is consistent with Misselhorn (2009) who highlighted the importance of considering locally understood proxies for social capital in food security interventions and more broadly to the importance of understanding context-specific interactions.

But how to integrate the local social capital system in targeting safety net is a question that should be answered. Responses obtained from informants, including experts, local food security taskforces, and mutual support group leaders, are summarized into two major categories. The first category was in favor of customizing the PSNP guidelines in line with the traditional system and suggests the inclusion of locally defined criteria of poverty as used in the local system for wealth classifications.

Addisu, 37 is a member of the taskforce. He said the following:

Such knowledge already exists within the community. The local categorization system is the same system the local government uses to categorize people based on their wealth level for different activities such as providing emergency food aid. Such methods should be used in the safety net program.

The second mechanism was to use selected mutual support groups as a vehicle in targeting the deserving beneficiaries. Respondents argued that the safety net program can target organized mutual support groups instead of individual households. Respondents cited historical evidence to support their argument. For instance, Abdella (a local elder), 85, remembers how working with local groups used to be a common practice during the socialist regime. He mentioned that organized mutual support groups such as burial groups, saving groups, and women's groups used to connect the poor to development agencies and provide reliable information about the poor.

In such a case, working with such groups can have several advantages: first, within each group information on targeting deserving beneficiaries is more readily available on program participants. This is likely to limit the problem of information asymmetry on the poor. Second, 
it avoids or at least minimizes targeting errors within existing groups, and this ensures the selection of the deserving beneficiaries. Third, by minimizing the cost of collecting information (that would have been otherwise spent in collecting information about the poor), it helps to redirect more resources to the poor. This finding is echoed by several studies (e.g., Clarke and Dercon 2009; del Ninno and Mills 2015; Dercon and Krishnan 2003) who also argued that working with local groups is an efficient way of reaching the deserving households in vulnerable communities.

\section{The role of social capital in safety net program}

The possibility to draw on bonding and bridging networks of kin, neighbors, and friends is an important welfare practice in Babile. The result shows that social networks facilitate the wider sharing of safety net resources to the community members, including those needy recipients excluded from the program. The redistributive role of social networks in the safety net program is clearly evident during the safety net "payment season," where you see an act of selfless generosity. During this time, children from beneficiary households will be busy delivering packages of cooked food, oil, and flour to the neighbors, relatives, and the elderly without a safety net.

To examine the redistributive effect of informal networks and whether safety net sharing takes place between households, we studied percentages of exchanges between and among beneficiaries and non-beneficiaries of the program. The majority of the beneficiaries interviewed (19 out of 30 households) shared up to a quarter of their payment (wheat and oil or cooked food) with less-privileged network members, such as family members and neighbors that were not targeted by the program (Fig. 1 below).

Such sharing took different forms and motives. Sometimes transfers are given out as part of a preexisting

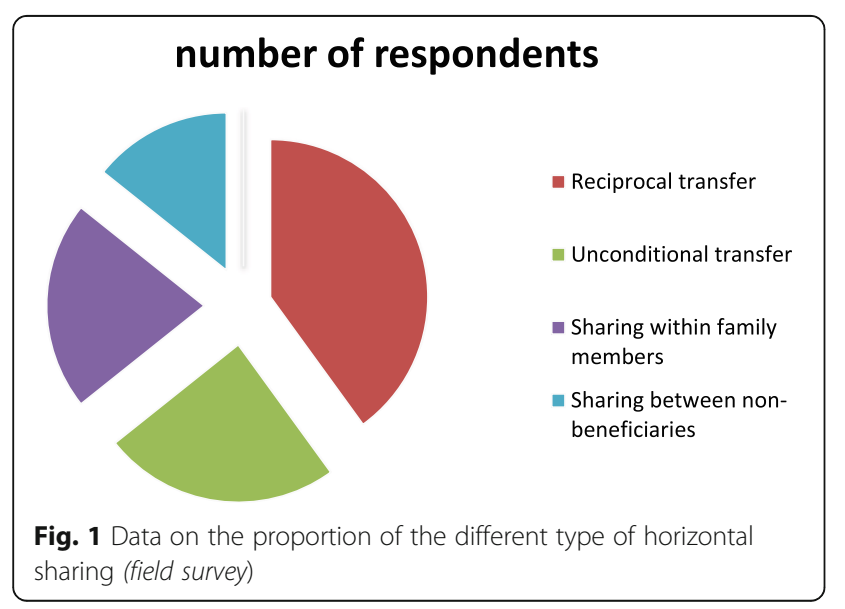

reciprocal transfer between households (this form of giving/receiving is reported by $40 \%$ of the respondents) - "I help you out today and you will help me tomorrow." This form of sharing is an insurance policy to get support next time. Transfers are also made to poorer households unconditionally (reported by $24 \%$ of the respondents) without expecting reciprocal favors in return. Some households shared a part of their quota to elderly and disabled neighbors and close kin that are in a desperate condition than themselves. Another form of sharing is the one that took place within family members (reported by $21 \%$ of the respondents). For instance, a safety net targeted for elderly parents trickledown to children without an income. In Babile, elderly beneficiaries mostly live among poor children or other caretakers. Sharing also took place between non-beneficiary households (14\% of the respondents). There were several examples whereby the non-beneficiary households shared the safety net received through informal sharing circles to less privileged family members or neighbors without a safety net. Such sharing represents a form of redistribution rooted in local social capital practices.

To emphasize this, Hindo, 35, is a female nonbeneficiary. She said the following:

My neighbors are my safety net. They always share with me what they get from the safety net program. I am always thankful to God for blessing me with such a selfless neighbors and living in such a supportive community. Whenever they receive their quota, they ensure that they share something with me.

This is evidence that the program excludes some of the most needy, but even in this circumstance, such households survive on their social capital. The social capital allows the redistribution of the benefits from the safety net program for those who are entitled but deprived because of the loopholes in identifying needy households. In so doing, social networks allow poorer households to access food and can also compensate for some of the targeting errors that were involved in the program. This finding is consistent with Amornsiriphong and Piemyat (2011) as well as Dercon and Krishnan (2003) who also noted that social capital and informal sharing networks function as means of a social safety net and social protection in poor communities and allow for the wide dispersal of program resources.

\section{Household social network characteristics and access to social safety net}

The above findings suggest the sharing of safety net resources through social networks. Such sharing is mediated by household social network characteristics. Under 
this section, we shall examine how household network characteristics, including social network size, network composition, and proximity of social networks, facilitate the sharing of social safety net resources.

\section{Regarding social network size}

The study found links between network size and access to an informal sharing of safety net. Non-beneficiary respondents having more bonding ties (with friends, family members, and neighbors) and bridging ties (particularly with households from other villages) who are receiving safety net were likely to receive safety net resources from more sources. Households that regularly participate in community activities across and within villages were likely to have bigger network size, hence more access to the social safety net transfer. Conversely, spatially disadvantaged and less socially connected households were the least likely to receive a social safety net transfer than very well-connected individuals. For instance, newly settled households from our samples had difficulties getting support not only for the safety net transfer but also for other types of support.

To emphasize this, one of the development agents said the following:

In most cases, mobilizing resources is conditional upon a household having the necessary linkages with community members. This requires individuals to socialize, build trust, and be accepted as an "active" member of the community. Being "active" also constitutes to live closer to people, regularly participate in community meetings, and attending funeral services.

This is evidence that social network size is a very crucial parameter in accessing safety net transfers from other households.

\section{Household network composition}

Family or kin, neighborhood, and belonging to same mutual support groups were the three most frequently reported network types in the sharing of the safety net resources. Family represents the most important source of support in Babile. In fact, most safety net shared to non-beneficiary households reported to have come through a bonding social networks of close family members or in-laws. It is reported that needy households that are having a network structure of more close family members receiving safety net were likely to receive more safety net transfer than networks composed of friends or acquaintances. The amount of transfer is also reported to be higher when safety net transfer (both given out and received) is made within networks of close kin as compared to safety net shared between networks of more distant relations. Neighborhood is another important relationship in the social safety net sharing. Living in a neighborhood network of more safety net beneficiaries provide the needy households with more access to an informal sharing of safety net resources. There is a religious and cultural perspective to this kind of sharing. Culturally, a neighbor has a special right and privilege from his neighbor's food-this also includes food from safety net transfer. For instance, it is considered a crime for the person to eat until he is full while his neighbor is starving. Even the customary law accords the person some right to file a complaint against such stingy neighbors. For this reason, food is widely considered communal and most times is used to strengthen relations and social capital for this matter. That is why it is a common practice throughout the case study community to dine outside of the house (so that they can be seen by neighbors). This is also an act of inviting a starving neighbor including a passerby to join in their plate.

In this connection, an elder once said the following:

The Babile's rarely build a fence or any kind of physical barriers between houses. Neighbors see each other not only as people living next to each other but also as a resource. You know, in our tradition, we first say 'Allah'/God and then, we say 'Olla' (neighbors); meaning next to God, who always comes for help is your neighbor. Sharing your food is the least one can do to nurture good relationship.

This indicates how neighbors or bonding capital provide those excluded from the safety net with more reliable access to program resources. This is an example of how the right to access food denied to the needy by the formal institution is safeguarded by traditional social norms that allow the sharing of food to needy neighbors through social networks. This way, neighborhood networks allow redistribution of the safety net to needy neighbors. This finding agrees with Bernier and Meinzen-Dick (2014) who reported the role of bonding social capital (networks composed of close networks of neighborhood and kin connections) in accessing useful resources in Ethiopia.

\section{Regarding social network proximity}

It is found that networks that provide the most resources between households were predominantly bonding types or located within the villages. This makes it difficult for some needy households to mobilize resources outside their villages. This was especially a challenge for the needy households residing in villages with a small number of safety net receiving households. The study findings show that some of the households that have more bonding and bridging connections with social 
safety net beneficiaries both from within and outside their villages were likely to receive more safety net resources.

In general, these findings suggest that social networks facilitate access to social safety net resources, including those needy households excluded from the program. This is mediated by the characteristics of social networks, including its size, composition, and proximity. At the same time, a variation arising from differences in the household social network characteristics may affect household's access to an informal sharing of safety net resources. These findings are consistent with Obaa and Mazur (2016) and Heemskerk et al. (2004).

\section{Household factors determining access to social networks and safety net resources}

Other than the network characteristics, inter-household differences (in terms of gender, education and wealth) influence household social networks for resource access. Such differences may, in turn, create and/or reinforce unequal access not only to informal sharing of safety net resources but also to target for the public safety net program. To understand how household characteristics affect access to social networks and hence, the public safety net, results were analyzed below separately-for formal safety net transfer through "informal sharing circles" and through "direct targeting."

\section{Household factors affecting social networks and access to safety net through "sharing networks"}

Generally, household social network characteristics are affected by household characteristics. Wealthier, better educated, and households with male heads were more likely to have diverse social networks as compared to poorer, less educated, and female-headed households (Table 1). Such differences in household social network characteristics arising from variations in household characteristics, in turn, reinforce variations in access to resources. This includes social safety net sharing received through horizontal networks. As indicated below (Table 1), nonbeneficiary households with poorer, less educated, and a female head received social safety net sharing from networks primarily located from within the local community. In contrast, non-beneficiary households with richer, better educated, and male household heads have received informal safety net transfer from social networks located both from within and outside the local community. This finding implies that different household characteristics may mean different types of connections and hence variations in access to safety net resources.

However, certain aspects of household characteristics require further contextualization. Though households with a male head on average have better access to social safety net transfer coming from networks located both within and outside the local community (see Table 1 above), households with a female head have better access to social safety net transfer from networks composed of kin, friends, and neighbors that are primarily located within the local community. The respondents (i.e., 62 out of 70 households) have indicated that households whose heads are a female were more likely to receive safety net sharing via a horizontal connection coming from close kin and neighbors primarily located within the villages. This is indicative that within the local community, women have more horizontal connections for accessing food-related items than male-headed households. This is shaped and facilitated by the traditional gender roles of women. For instance, traditionally interhousehold reciprocities involving food-related items are the responsibility of women since they are also primarily responsible for cooking and managing the household's food. Men on the other hand mainly engage in reciprocities for labor or cash. With food sharing predominantly considered to be woman's role, it is not thus surprising that female-headed households have more access to the social safety net transfer coming from informal networks.

\section{Household factors affecting social network and access to safety net program through "direct targeting"}

Some of the household characteristics that affect social network characteristics for accessing safety net resources (through informal sharing between households) discussed above also influence the ability to access social safety net program through direct targeting which requires vertical social networks. Field data suggested that inter-household differences in access to vertical connection suggest variations to target for social safety net program among households. To measure vertical connection for beneficiary and non-beneficiary households, respondents were asked one common question: do you know someone or are you somehow related to a person among the food security taskforces (such as development agents, local leaders, community food security taskforces or higher official)? If the answer to this question is a yes, then the person will be requested to indicate the type/nature of relationships (such as kin, friends, acquaintances, and the friend of a friend). Based on these questions, we found important linkages between having a vertical connection and the ability to target for a safety net program. For instance, the majority of current beneficiaries (21 out of 30 households) were vertically connected to either one of the food security taskforces or had someone outside the taskforces who can help to lobby for them.

Further, to understand the significance of having one of these vertical ties, households were asked to rank the different types of vertical connections based on their level of importance to target for safety net program 


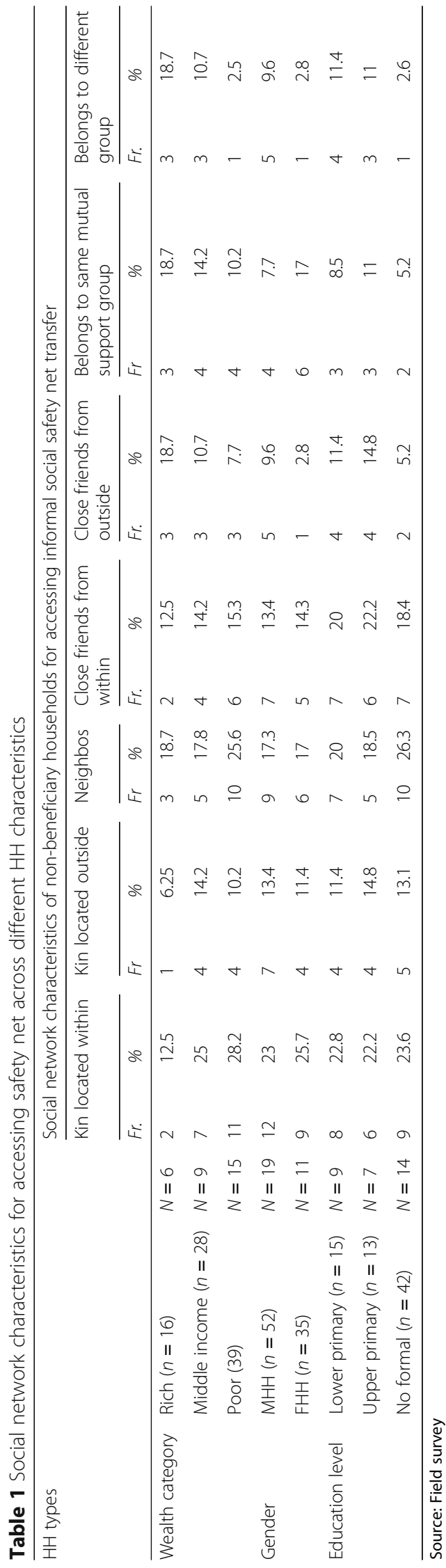


(Fig. 2 below). The results show that households in whose social networks have a close kin from among one of the food security taskforces were considered to be at an advantaged position to target for safety net program (ranked by 35\%) as compared to having a close friend with one of the food security taskforces (26\%). Similarly, having someone in one's network (official from the food security office or someone with important political position) outside the taskforces is considered to be the third most important vertical connection to target for safety net program (ranked by 25\%). Personal acquaintances with one of the food security taskforces is with the least significance. If someone was both a close kin and friend with one of the food security taskforces as well as knows some authorities simultaneously, the relationship was considered most important to target for safety net program.

Finally, to examine the interhousehold variations in access to social networks and hence the public safety net, household's wealth level, gender, and levels of education were considered. In relation to wealth, we found indications that suggest links between household wealth level, access to social networks, and safety net program. However, this is not in a way that one would normally expect, namely, a safety net to be allocated for resourcepoor households and with limited access to social networks. Several households (32 out of 70 respondents) have reported that the household's ability to target for the safety net improves with improved asset holding. Wealthier households have more chances to vertically connect with the food security taskforces and target for the safety net program. This is also supported by data obtained from observations and interviews. For instance, within the villages, the ability to establish a vertical network with the DAs to targeting for safety net program increases with the ability to regularly host local food security taskforces at one's house. And this mostly improves with having good houses, the ability to cook good meals, buy bottled water, and serve good coffee and milk to the DAs.

To emphasize this, a woman once said the following:

It is not only your actual need for food that matters, but also your connection with the DAs. And this requires a sacrifice a poor person like me cannot afford -a good house and a clean meal. I wouldn't have applied for safety net if I had those things in the first place.

The above is an example of how variations in household's access to a certain type of social networks (notably vertical networks) arising from the differences in household asset holding exclude the poorest households to target for a public safety net. Such is an example of corrupt institutional practices that put actors in an asymmetric relationship of hierarchy, dependence, and exploitations. This finding is consistent with Petrikova and Chadha (2013) and Caeyers and Dercon (2012) who found that people with vertical social networks were more likely to be part of a social program.

Access to a public safety net can be reinforced by household's educational level. The household's "negotiating capacity" in targeting for the social safety net, here defined as a function of a household's capacity to access "vertical networks" for linking with the food security taskforce, increases with education. The ability to manipulate personal networks and understand the bureaucratic procedures involved in the safety net program is often found to be pivotal in targeting for PSNP in the study site. "Better educated households can easily network and establish personal relationships with DAs and other food security taskforces", said one of the senior food security experts from Babile. By their connections with the food security taskforces, they can successfully navigate through the bureaucratic procedures involved in the program. For instance, one of the biggest

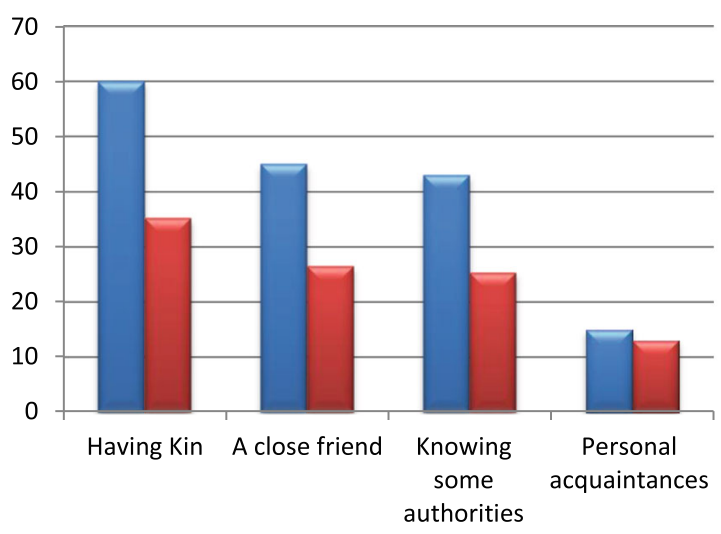

Number of

respondents

Dercentage

Fig. 2 Household ranking of vertical ties for safety net targeting (field survey) 
challenges in access to the safety net program is the availability of adequate information on the eligibility criteria and the extent to which it is understood by the local people. Better educated households, that are also closer to the Das, have more capacity to navigate through the bureaucratic procedures successfully, acquire more information, and better understand the eligibility criteria. This, in turn, allows them to better negotiate and even challenge decisions regarding the outcome of targeting.

To explain this situation an elder said the following:

Several households that could have been eligible did not claim for the safety net simply due to the lack of adequate information on eligibility criteria. Most households would not even ask the reason for their rejections. The educated people among us are the bravest. They confront DAs. They speak during community meetings. To avoid facing confrontations with educated individuals, the DAs mostly stay in their company and facilitate their enrollment in the program.

Such cases demonstrate how the household's level of education may influence the ability to access certain types of connections to target for a safety net program. Though a better educational level empowers the vulnerable to understand the eligibility criteria and fight mischiefs, it should not count as a factor in targeting for the safety net program. Uneducated households with the real felt need for food assistance must not be discriminated against due to their inability to vertically network with the targeting agencies. This is also consistent with Heemskerk et al. (2004) who found that education and centrality in community networks influence not only access to social capital but also access to the public safety net.

Gender-based differences in access to social networks between men and women also suggest variations in access to the safety net program. Several respondents (41 out of 70 households) have reported that a household whose head is a female is likely to experience difficulties to target for PSNP. This is despite the fact that women, including single mothers, widowed women, and elderly women represent the disproportionate majority of the poor households in the localities. This disparity to target for the safety net program is manifested by the number of male and female beneficiaries in the program. For instance, of all the program beneficiaries, women account only less than $10 \%$. Such a lack of representation of women in the program is partially due to the differences between men and women in accessing important information on the eligibility criteria, which mostly requires establishing a vertical network with the targeting agencies. In most cases, women are shy in contacting one of the food security taskforces for possible guidance. Even in the cases of targeting exclusions or premature graduation (early evictions from the program), which female-headed households frequently face, women are less likely to make a successful appeal. One of the nonbeneficiary respondents said, "Women would find it difficult in navigating through the bureaucratic procedure in making a successful appeal, which also requires having connections and the public speaking ability that women rarely possess." Women's access to the social safety net program is also constrained by structural factors. For instance, to target for a safety net program within the villages often requires households to actively participate in compulsory meetings and campaigns organized by the DAs office. It is reported that (43 out of 70 households) a household's visibility for being recommended for the safety net program increases as they regularly participate in such activities, connect with the food security taskforces, and gain more social capital. However, women face difficulties in attending such activities and connecting with food security taskforces as compared to men. Nearly all women respondents have underscored that they do not have the leisure time to participate in such activities as they are too busy with domestic responsibilities.

In general, the findings based on the household variables suggest that a household's ability to target for a safety net program is affected by access to social networks, which, in turn, is mediated by household-level factors such as education, gender, and asset endowments. Such differences often work to the disadvantage of the poorest households, such as women and other resource-poor households. Thus, it is important that social safety net targeting should consider these groups of households. This finding is consistent with Devereux et al. (2017), Misselhorn (2009), and Heemskerk et al. (2004) who noted the importance of considering household-level factors and the inclusion of social capital based indices in targeting safety net program.

\section{Policy implications and conclusions}

This study aimed to examine the role of social capital in targeting a safety net intervention in vulnerable communities in eastern Ethiopia. The findings on the role of social capital show the redistributive roles of social capital (bonding and bridging types) in the safety net interventions. The presence of mutual sharing networks has an additional effect that can improve the targeting efficiency of the public safety net program. This is mediated by the cognitive and structural elements of social capital and the characteristics of social networks, including its size, composition, and proximity. This finding is consistent with Dercon and Krishnan (2003) as well as Clarke and 
Dercon (2009) who reported that the presence of a public safety net transfer to some households in the community has an extra effect on consumption for non-targeted households due to a wider reallocation of social networks. This suggests that social networks can result in better efficiency of the distributions and coverage of social assistance programs and compensates for some of the adverse selection errors involved during beneficiary identification.

At the same time, inter-household differences in access to social networks mediated by household level factors, such as gender, education, and wealth, can reinforce and/ or create unequal access to target for the social safety net transfer. Surprisingly, a household's ability to target the social safety net program improves as they gain the ability to access more vertically connections with the food security taskforces, and this improves with improved literary abilities, familiarity with bureaucratic procedures, and improved household asset holding. Such differences sometimes exclude and discriminate against most marginal groups including women and other resource-poor households that cannot access vertical networks. This finding is consistent with Heemskerk et al. (2004) who found evidence that power and relational differences that exist between households generate unequal access not only to social capital but also to target for the safety net program, which is, in theory, indiscriminate. A social safety net available for those with the most social capital and household assets defeats the purpose of the safety net program. Instead, it creates inequality and jealousy among community members and may affect the future cooperative behavior between beneficiaries and non-beneficiaries of the safety net program (Bernier and Meinzen-Dick 2014; Getachew et al. 2018). However, none of these suggest the "dark sides" of social capital as evidenced by Compton (2018) and Di Falco and Bulte (2011). Instead, this shows the presence of a corrupt institutional system that manipulates existing systems/social capital of the poor and puts actors in an asymmetric relationship of hierarchy and exploitations.

To reiterate, our findings show that access to a functional and diversified social capital resources by households (bonding, bridging, and linking) can lead to improved social safety net effectiveness. This is contrary to the findings by Compton (2018) who found no evidence of social capital leading to improved social welfare effectiveness. Our evidence suggested that the wide presence of local social capital practices can improve effectiveness of social welfare interventions. This is in line with the theories of social capital as articulated by Woolcock and Narayan (2000) and Putnam (2000) that social capital improves the effectiveness of development interventions. It is thus important to promote social capital. A failure in social capital can trigger a failure in a public intervention and undermine the design of sustainable safety net programs.

As far as the implication of these findings in the targeting of effective humanitarian responses is concerned, integrating a social capital perspective in the early design and implementation of a social safety net program could help improve the targeting of a social transfer program for those with the most need. Since the lack of social capital is also associated with the vulnerability of some households when it comes to accessing the social safety net, the inclusion of social capital proxies (both during the beneficiary selection and impact evaluations) can help in targeting the most needy households and evaluate its impact on the social capital of the poor. Gender-sensitive social safety net targeting and program design aimed at improving the social capital and asset holding of women and other vulnerable groups could help enhance the resilience of resource-poor. This decision can be guided by gender-disaggregated information and household social network maps showing interhousehold differences in access to social capital resources. This may include identifying the type of networks possessed by each household and their network relationships with the targeting agencies.

In conclusion, the reform towards regular, long-term, and predictable social safety nets of resources is a commendable act in assisting the poor build their resilience to shocks. But such actions should not undermine the role of indigenous informal safety nets and the social networks in targeting the program. The paradigm advocated in this study proposes a social capital perspective to development assistance and engage the affected communities in the process of targeting the safety net intervention. Social transfer programs can better target the poorest household if they improvise their targeting criteria based on the indigenous knowledge system and the social context these interventions are embedded under. This will require policy-makers and agencies to recognize and appreciate that communities have distinct notions of social justice. Working closely with mutual support group leaders can increase the availability to lower the cost of information on the targeting of the most needy household, redirect more resources to the poor, and minimize conflict between community members. In this regard, an important direction for future research is to examine how social capital and the local knowledge system can be effectively integrated into the effective localization of humanitarian response in vulnerable communities. In-depth research is also required to identify which aspects and characteristics of social capital are useful for targeting targeted interventions.

\section{Acknowledgements}

The authors are grateful to Rajesh GK for reading and commenting on the draft paper. We are also grateful to Prof. Conny Almekinders of Wageningen 
University, the Netherlands, for her scholarly contributions at the early inception of the study in 2014.

\section{Authors' contributions}

GS has immensely contributed to the conception, design, data collection, coding and analysis and interpretation of the data, and drafting of the manuscript. PK made substantial contribution to the analysis of data and revision of the manuscript for important intellectual content. BO made significant contributions to the analysis of the data and revision of the manuscript for important intellectual content. JY made significant contributions to the conception and design of the study and revision of the manuscript for important intellectual content. All authors read and approved the final manuscript.

\section{Authors' information}

The authors choose not to provide this information.

\section{Funding}

No funding was received for this research.

\section{Competing interests}

The authors declare that they have no competing interests.

\section{Author details}

${ }^{1}$ Department of Rural Development and Agricultural Extension, Haramaya University, Diredawa, Ethiopia. ${ }^{2}$ Department of Extension and Innovation Studies, Makerere University, Kampala, Uganda.

Received: 13 September 2019 Accepted: 21 June 2020

Published online: 24 July 2020

\section{References}

Aldrich P, Meyer A (2015) Social capital and community resilience. J Am Behav Sci 59:254-269 https://doi.org/10.1177/0002764214550299

Amornsiriphong S, Piemyat S (2011) Social capital: means of social safety net and social protection in Thai communities. Procedia Eng 32:1152-1156

Aredo D (2010) The Iddir: an informal insurance arrangement in Ethiopia. J Sav Dev 34:53-72

Atkinson P, Hammersley M (2007) Ethnography: principles in practice. Taylor and Francis Group, New York

Ballet J, Sirven N, Requiers-Desjardins M (2007) Social capital and natural resource management: A critical perspective. Environ Dev 16:355-374

Beebe J (2001) Rapid Assessment process: an introduction. AltaMira, Walnut Creek

Bernier Q, Meinzen-Dick R (2014) Networks for resilience: the role of social capital. IFPRI, Washington DC https://doi.org/10.2499/9780896295674

Bhattamishra R, Barrett C (2010) Community-based risk management arrangements: a review. World Dev 38:923-932

Bourdieu P (1986) The Forms of Capital. In: Richardson JG (ed) Handbook of theory and research for the sociology of education. Greenwood Press, Westport, pp 241-258

Brayman A, Burgess RG (2005) Reflections on qualitative data analysis. In: Brayman A, Burgess RG (eds) Analyzing qualitative data, vol 25. Routledger, pp 217-220

Brewer J (2000) Ethnography. Open University Press, Buckingham

Caeyers B, Dercon S (2012) Political connections and social networks in targeted transfer programs: evidence from rural Ethiopia. J Econ Dev Cult Change 60(4):639-675. https://doi.org/10.1086/665602

Calder R, Tanhchareun T (2014) Informal social protection: social relations and cash transfers (A research report). Retrieved from http://www.dfat.gov.au

Clarke D, Dercon S (2009) Insurance, credit and safety nets for the poor in a world of risk (Working paper No. 81. Oxford University, UK. ST/ESA/2009/DWP/81). Retrieved from https://www.un.org/esa/desa/papers/2009/wp81_2009.pdf

Coleman J (1988) Social capital in the creation of human capital. Am J Sociol:95$120 \mathrm{https}: / /$ doi.org/10.1086/228943

Compton EM (2018) Less bang for your buck? How social capital constrains the effectiveness of social welfare spending. State Polit Policy Q 18(3):215-245. https://doi.org/10.1177/1532440018775424

Creswell WJ (2007) Qualitative inquiry and research design: choosing among five traditions. Sage, Calif del Ninno C, Mills B (2015) Safety nets in Africa: effective mechanisms to reach the poor and most vulnerable. World Bank, Washington, DC https://doi.org/ 10.1596/978-1-4648-0435-9

Demissie B, Kasie T (2017) Rural Household's vulnerability to poverty in Ethiopia. J Poverty 21:528-542 https://doi.org/10.1080/10875549.2017.1348425

Dercon S, Krishnan P (2003) Food aid and informal insurance. Insur Against Poverty. https://doi.org/10.1093/0199276838.003.0015

Devereux S, Getu M (2013) Informal and formal social protection systems in SubSaharan Africa. Fountain publishers, Uganda

Devereux S, Sabates-Wheeler R, Tefera M, Taye H (2006) Ethiopia's Productive Safety Net Programme (PSNP): Trends in PSNP transfer within targeted households. Final report. Institute of Development Studies, Sussex, UK

Devereux $S$ et al (2017) The targeting effectiveness of social transfers. J Dev Eff 9: 162-211 https://doi.org/10.1080/19439342.2017.1305981

Di Falco S, Bulte E (2011) A dark side of social capital? Kinship, consumption, and savings. J Dev Stud 47(8):1128-1151 https://doi.org/10.1080/00220388.2010. 514328

Gentilini U, Omamo S (2009) Unveiling social safety nets. World food Programme (Occasional paper NO. 20). World Food Program, New York

Getachew SE, Kibwika P, Obaa BB, Hassan JY (2018) Does the implementation of social safety net intervention affect indigenous social capital systems for coping with livelihood shocks? Ethnographic evidence of agro-pastoral communities in eastern Ethiopia. In: Efobi U, Asongu S (eds) Financing sustainable development in Africa. Palgrave Macmillan, Cham

Gibbons P, McDermott R, Maitra S, Herman J (2017) Building on the capacities of crisis-affected populations: from victims to actors. Dev Policy Rev:1467-7679 https://doi.org/10.1111/dpr.12239

Grootaert C, van Bastelaer T (2002) Understanding and measuring social capital: a synthesis of findings and recommendations from the social capital initiative (World Bank Working paper series No. 24). World Bank, Washington, DC

Grosh M, del Ninno C, Tesliuc E, Ouerghi A (2008) For Protection and Promotion: The design and implementation of effective safety nets. World Bank, Washington, DC

Hardy C, Harley B, Phillips N (2004) Discourse analysis and content analysis: two solitudes? Qual Multi-methods Res 2:19-22 https://doi.org/10.5281/zenodo. 998649

Heemskerk M, Norton A, de Dehn A (2004) Does public welfare crowd out informal safety nets? Ethnographic evidence from rural Latin America. World Dev 32:941-955 https://doi.org/10.1016/j.worlddev.2003.11.009

Hoddinott J et al (2011) Evaluation of Ethiopia's food security program: documenting progress in the implementation of the PSNP. International Food Policy Research Institute, Washington, DC

Kebede W (2012) Women, social networks, and HIV. J Community Pract 20:52-68 https://doi.org/10.1080/10705422.2012.648077

Kebede W, Butterfield AK (2009) Social networks among poor women in Ethiopia. Int Soc Work 52:357-374

Long N (2001) Development sociology: actor perspective. Routledge, London

Marsden V, Campbell E (1984) Measuring tie strength. Soc Forces 63:28-501

Misselhorn A (2009) Is a focus on social capital useful in considering food securityinterventions? Insights from KwaZulu-Natal. Dev South Afr 6:89-208 https://doi.org/10.1080/03768350902899454

Monchuk V (2014) Reducing poverty and investing in people: the new role of safety nets in Africa. Directions in development. World Bank, Washington, DC https://doi.org/10.1596/978-1-4648-0094-8

Mouw T (2006) Estimating the causal effect of social capital: a review of recent research. Annu Rev Sociol 32:79-102 https://doi.org/10.1146/annurev.soc.32 061604.123150

Mpanje D, Gibbons P, McDermott R (2018) Social capital in vulnerable urban settings: an analytical framework. J In Hum Action 3(4):1-14 https://doi.org/ 10.1186/s41018-018-0032-9

Obaa B, Mazur R (2016) Social network characteristics and resource access among formerly displaced households in Lira, Uganda. Disasters. https://doi. org/10.1111/disa.12210

Ortlipp M (2008) Keeping and using reflective journals in the qualitative research process. Qual Rep 13:695-705

Pankhurst A, Damen H (2000) The Iddir in Ethiopia: Historical development, social function, and potential role in HIV/AIDS prevention and control. J Northeast Afr Stud 7(2):35-57

Patel L, Kaseke E, Midgley J (2012) Indigenous welfare and community-based social development: lessons from african innovations. Community Pract 20: 12-31 https://doi.org/10.1080/10705422.2012.644217 
Petrikova I, Chadha D (2013) The role of social capital in risk-sharing: lessons from Andhra Pradesh. J South Asian Dev 8:359-383. https://doi.org/10.1177/ 0973174113504848

Putnam R (1993) The prosperous community: social capital and public life. Am Prospect 13:35-42

Putnam R (2000) Bowling alone: the collapse and revival of American community. Simon and Schuster publishers, New York

Woolcock M, Narayan D (2000) Social capital: implications for development theory, research and policy. World Bank Res Obs 15:225-249 https://doi.org/ 10.1093/wbro/15.2.225

World Bank (2012) Managing risk, promoting growth: developing systems for social protection in Africa: the World Bank's Africa Social Protection Strategy 2012-2022. World Bank, Washington, DC

World Bank (2013) Ethiopia's Productive Safety Net Programme (PSNP). Integrating disaster and climate risk management. World Bank, Washington, DC

\section{Publisher's Note}

Springer Nature remains neutral with regard to jurisdictional claims in published maps and institutional affiliations.

\section{Submit your manuscript to a SpringerOpen ${ }^{\mathcal{O}}$ journal and benefit from:}

- Convenient online submission

- Rigorous peer review

- Open access: articles freely available online

High visibility within the field

- Retaining the copyright to your article

Submit your next manuscript at $\boldsymbol{\nabla}$ springeropen.com 